\title{
Experimental study on incipient shear stress of consolidated cohesive sediment
}

\author{
Caiwen Shu ${ }^{1} \cdot$ Guangming Tan ${ }^{1} \cdot$ Peng Chen ${ }^{2} \cdot$ Jun Wang $^{2} \cdot$ Ping $\mathrm{Lv}^{3}$ \\ Received: 15 April 2019 / Accepted: 3 September 2020 / Published online: 15 September 2020 \\ (C) The Author(s) 2020
}

\begin{abstract}
This paper analyzes the incipient motion mechanism of consolidated cohesive sediment. An experimental device based on previous studies was designed to investigate the influencing factors of the incipient shear stress, including the consolidation time, the density of dry bulk, cohesive particles content, and the composition of sediment mixtures. The experimental results indicated that the incipient shear stress of cohesive sediment increased with the increase of consolidation time, dry bulk density, and content of cohesive particles. The incipient motion mechanism of cohesive particles was further investigated using experimental data and theoretical analysis. A formula of the incipient shear stress for cohesive sediment was proposed herein, which is related to both the content of cohesive particles and the relative dry bulk density. The proposed formula was validated by the experimental data, and the calculated values of incipient shear stress using the formula were in good agreement with the experimental results.
\end{abstract}

Keywords Cohesive sediment $\cdot$ Incipient shear stress $\cdot$ Consolidation time $\cdot$ Dry bulk density $\cdot$ Incipient shear stress

\section{Introduction}

Understanding the incipient motion of sediment particles in sediment transport is of vital scientific importance to understand the incipient threshold of different properties sediment

Responsible Editor: Zeynal Abiddin Erguler

Caiwen Shu

cwshu@163.com

$\triangle$ Peng Chen

ChenPeng5211@outlook.com

Guangming Tan

Tangm958@outlook.com

Jun Wang

azy43@sina.com

Ping LV

lvping1997@163.com

1 State Key Laboratory of Water Resources and Hydropower Engineering Science, Wuhan University, Wuhan 430072, China

2 Key Lab. of River Regulation and Flood Control of Ministry of Water Resources, Changjiang River Scientific Research Inst., Wuhan 430010, China

3 Anhui Bureau of Yangtze River Management, Wuhu 241000, China under various flow conditions. Also, it is of practical importance for channel sediment transportation, bank stabilization, development and management of deltas and coasts, aggradation/erosion in the upstream and downstream of the reservoirs, and so forth. When the flow-induced shear stress exceeds a certain critical value, the bed particle begins to move, and the shear stress in this situation is defined as the incipient shear stress, which equals to component force of water weight on unit bed surface in the flow direction. Shields curve is widely known for commutating critical shear stress of uniform cohesionless sediment (Singh et al. 2017). However, the relationship between the cohesive of sediment particle and the range of consolidation has been neglect. Subsequently, the following model studies have been conducted to understand the characteristics of the incipient shear stress of consolidated cohesive sediment.

In addition to common properties of sediment, cohesive sediment is characterized by clay particles with large specific surface areas. Higher complexity of the incipient motion and scouring mechanism of cohesive sediment is induced compared with those of noncohesive sediment, because the surface of cohesive particles in water is strongly influenced by the physical and chemical action (Tan et al. 2007b; Zhang et al. 2009; Wang and Cai 2014; Tan and Chen 2016). 
The incipient motion of cohesive sediment has been extensively studied (Dune 1959; Chien and Wan 1999). Since 1962 , many experiments testing the erosion process of cohesive sediment bed that were deposited from suspension have been conducted, including those by Mehta (1973), Mehta and Partheniades (1975), and Krone (1962, 1993). In the 1990s, the values of critical shear stress were measured in various experiments (McNeil et al. 1996; Liem et al. 1992; Roberts and Lick 1997, 1998a, b, 1999). In general, a full consolidation process involves flocculation, deposition, erosion, transport, and consolidation (Wu et al. 2004). A critical bed shear stress to initiate erosion was essential for the setup of numerical models. Toorman (2002) and Winterwerp (2002) found that different water depths hardly influenced the process of deposition for cohesive sediment. In situ erosion experiments were carried out in the York River by Maa and Kim (2002). They found that minimal variation of the critical bed shear stress for starting erosion showed at the water-sediment interface, while significant increase of the critical bed shear stress for the well-consolidated sediment occurred below the interface. To represent distribution of the bed shear stress, a probability function was used by Winterwerp (2007). Mehta and Partheniades (1975) simulated the experimental results by Krone (1962) successfully. Maa et al. (2008) studied the critical shear stress for cohesive sediment bed under steady flow. Wang and $\mathrm{Hu}$ (2009) suggested a critical velocity for the scouring of cohesive sediment from the Zhuwo Reservoir as a function of the deposition dry bulk density, which is being expressed as:

$U_{c}=4.6\left(\rho^{\prime}\right)^{4}$

where $U_{c}$ is the critical velocity, and $\rho^{\prime}$ is the dry bulk density. An empirical formula was proposed by $\mathrm{Xu}$ et al. (2015), for the critical velocity of coastal muds at different densities, which indicated that the incipient shear stress grows exponentially with mud density. Zheng and An (2017) reanalyzed data from two experiments and found that the critical shear stress depends on bulk density and clay solid content using the data in the work of Sharif (2003), while result from Kothyari and Jain (2008) demonstrated that the critical shear stress of cohesive sediments varied with the clay solid content and clay volume content in the presence of gravel and air.

However, due to short consolidation times, different impacts of consolidation characteristics on the starting motion of cohesive sediment cannot be effectively revealed in Eq. (1). Moreover, the consolidated cohesive sediment taken from the field sites was scoured by a jet flow at the laboratory. Thus, a disturbance to the original sediment sample may affect the inner stable structure of deposition.

Hence, in this study, to improve the experiment for the two shortcomings described above, a pressure pipe system was established to conduct the incipient motion experiments of cohesive sediment with different consolidation time. Various effects of consolidation time, dry bulk density, and content of cohesive particles on the incipient motion were investigated by experiments, and a new incipient motion formula of cohesive sediment was proposed. The experiments results and theoretical analysis obtained in this study may help to deepen the understanding of the mechanism of the incipient motion of consolidated cohesive sediment.

The present study aims to measure and quantitatively explore the effects of consolidation on the critical conditions of incipient motion of cohesive sediments. Laboratory experiments were performed in a rectangular PMMA glass pipe and the influences of bulk density, water content, and yield stress on the incipient motion were systematically investigated. More specifically, the experimental material, equipment, and methodology are introduced in the "Experiments" section. In the "Influencing factors on incipient shear stress of cohesive sediment" section, the results are presented, and the influences of the various factors are compared and analyzed, especially the influence factors on incipient shear stress of cohesive sediment. In the "Incipient motion formula of cohesive sediment" section, an empirical formula for the critical parameter and a modified Shields diagram are proposed based on the experimental data, and some suggestions for further study are discussed. Finally, the "Conclusions" section presents the main conclusions of the study.

\section{Experiments}

\section{Experimental setup}

A long consolidation time can help cohesive sediment resist large flow shear stress. It is difficult for an open channel flume to steadily provide the necessary conditions for the incipient motion of cohesive sediment. For this reason, a special experiment setup was designed that consisted of a rectangular PMMA glass pipe as shown in Fig. 1. And the pipe is $3-\mathrm{cm}$ wide and $12-\mathrm{cm}$ long. The sediment samples were placed in a test cylinder with the same size as the test sample. The inner diameter of the test cylinder was $7 \mathrm{~cm}$. Two piezometric tubes were installed $0.6 \mathrm{~m}$ upstream and $0.6 \mathrm{~m}$ downstream from the test cylinder, respectively. A rubber piston below the cylinder was used to push sediment samples upwards in the cylinder. In the experiments, in order to keep the sample surface and pipe bottom at the same level, a manual elevating screw was used to control the rubber piston so that the sample height could be adjusted according to the scouring situation. 
Fig. 1 Schematic view of the experimental installation

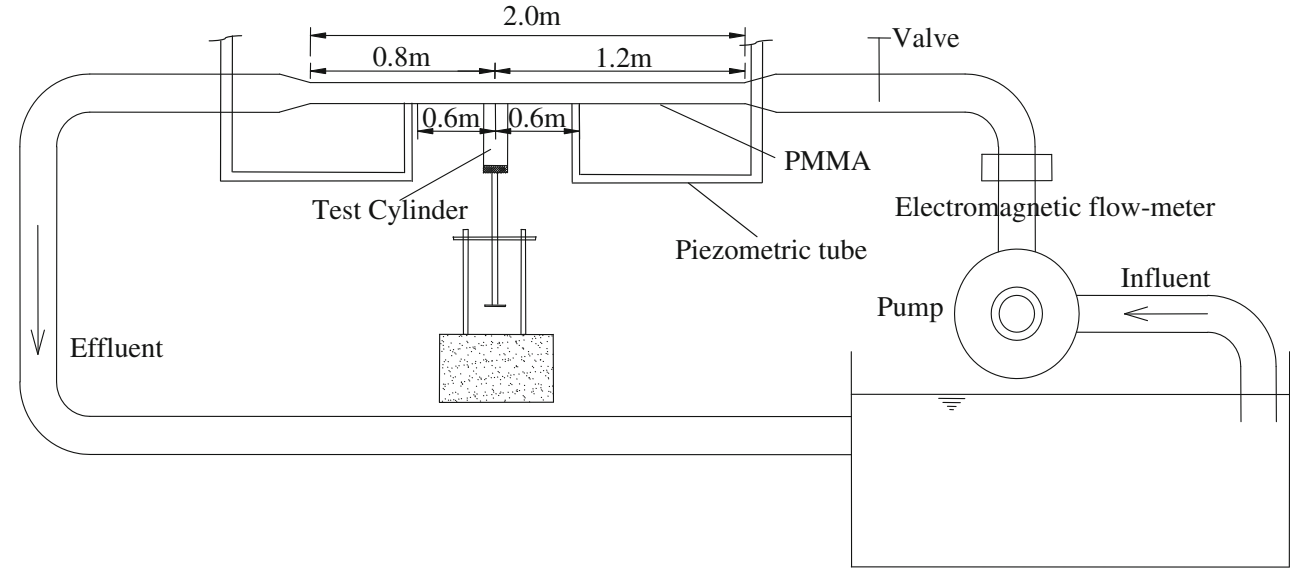

\section{Sediment samples}

The sediment samples to be tested were selected from the deposition at Huayuankou in the Lower Yellow River as well as from the Yangtze River. Sediment samples collected from Lower Yellow River are mostly Kaolinite and Montmorillonite, and that from Yangtze River are mainly Illite and Kaolinite, the detailed properties being given in Table 1. For the four groups of tested sediment samples, 12 of different consolidation time for each group were selected, a total of 48 data sets were analyzed. The consolidation time in the experiments was 1 day, 3 days, 5 days, 8 days, 13 days, 21 days, 34 days, 55 days, 89 days, 144 days, 233 days, and 377 days, respectively. Table 1 shows the details of all data sets that were collected from these laboratory experiments; D50 represents median sediment size, is cohesive particles content, is dry bulk density, and represents incipient shear stress. These two kinds of cohesive sediment were divided into four groups using the sieving and sedimentation methods as follows: (i) group A was the sediment deposition from the Yangtze River with particle sizes smaller than $0.10 \mathrm{~mm}$; (ii) group B was the sediment deposition from the deposition in the Lower Yellow River; and (iii) mixing group $A$ with group $B$ in the ratio of 5:1 and 2:1 was taken as groups $C$ and $D$, respectively. The size distribution curves of these four groups are shown in Fig. 2. Median sediment size of groups A, B, C, and D is $0.046 \mathrm{~mm}$, $0.008 \mathrm{~mm}, 0.042 \mathrm{~mm}$, and $0.038 \mathrm{~mm}$, respectively. Sediment with diameter finer than $0.005 \mathrm{~mm}$ in this study is defined as cohesive particles, and cohesive particle content is taken as weight percentage of cohesive particles to all the sediment. Cohesive particle content in groups A, B, C, and D is $2 \%$, $38 \%, 8 \%$, and $15 \%$, respectively.

\section{Consolidation experiment}

The whole process of consolidation experiment is described as follows: First, the prepared sediment sample was put into a plastic basin after being uniformly mixed. Clear water (tap water) was sucked out as the clear water percolated slowly during the free settling stage of the sediment. Secondly, the deposition in the plastic basin was mixed uniformly by continuous whisking, and it was then put into separate sample containers. Thirdly, these sample containers were submerged in a water pool, and thus, various consolidation processes under the water surface were conducted, with different consolidation times ranging from 1 to 377 days. The sediment sample in each container was taken out for the incipient motion experiment.

Before the incipient motion experiment, sediment sample container was put on the top of experimental device firstly, one side of the container was removed, and then, the experimental device was rising slowly until all the sediment sample went into the test cylinder. This ensured that the sediment sample could not be disturbed during the whole period of
Table 1 Summary of collected data

\begin{tabular}{llllllll}
\hline Group & Run & $\begin{array}{l}D_{50} \\
(\mathrm{~mm})\end{array}$ & $\begin{array}{l}P_{c} \\
(\%)\end{array}$ & $\begin{array}{l}\rho^{\prime}\left(10^{3} \mathrm{~kg} /\right. \\
\left.\mathrm{m}^{3}\right)\end{array}$ & $\begin{array}{l}\text { Incipient velocity } \\
(\mathrm{m} / \mathrm{s})\end{array}$ & $\tau_{c}\left(\mathrm{~N} / \mathrm{m}^{2}\right)$ & $\begin{array}{l}\text { Water temperature } \\
\left({ }^{\circ} \mathrm{C}\right)\end{array}$ \\
\hline $\mathrm{A}$ & 12 & 0.046 & 2 & $1.20 \sim 1.28$ & $0.28 \sim 0.38$ & $0.30 \sim 0.47$ & $16 \sim 20$ \\
$\mathrm{~B}$ & 12 & 0.008 & 38 & $0.74 \sim 0.84$ & $0.82 \sim 1.67$ & $1.91 \sim 5.86$ & $16 \sim 20$ \\
$\mathrm{C}$ & 12 & 0.042 & 8 & $0.90 \sim 1.22$ & $0.44 \sim 0.97$ & $0.63 \sim 2.21$ & $16 \sim 20$ \\
$\mathrm{D}$ & 12 & 0.038 & 15 & $0.87 \sim 1.14$ & $0.56 \sim 1.13$ & $0.98 \sim 3.02$ & $16 \sim 20$ \\
\hline
\end{tabular}

The cohesive particle denotes sediment with diameter finer than $0.005 \mathrm{~mm}$ (Sediment Specialty Committee of CHES 1992; Lin 1992) 


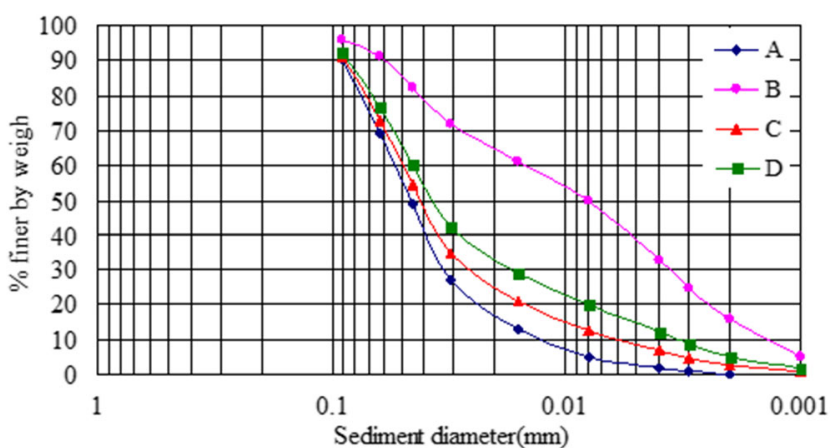

Fig. 2 Size distributions of samples

experiment, because experiment operation-induced disturbance was avoided to the great extent, as sediment sample was put on the device top and went to the test cylinder gently.

In order to analyze the change of the dry bulk density of cohesive sediment during the consolidation process, another consolidation experiment of a tested sediment sample was also carried out in a measuring cylinder.

\section{Scour experiment}

A series of experiments have been carried out at the Experimental Hall of Sedimentation and Flood Control, Wuhan University, in order to investigate the incipient shear stress of cohesive sediment under different consolidation times.

The scour experiment procedure is, firstly, the sample was placed in the bottom inlet, and then made sample surface a little higher than the conduit bottom by pushing the sample up. Secondly, to ensure the conduit was fulfilled by water and the sample could be scoured, the power of a pump was increased gradually until the pump reached a specified flow rate. Thirdly, when an intermittent but discernable change occurred on the deposition surface, such as the intermittent patches or local pits, the flow shear stress in the pipe was regarded to be equal to the critical incipient shear stress of cohesive sediment. When the sample was scoured, it was pushed up gradually so that its surface was always level with the conduit bottom. Finally, the results of the experiment were recorded. It should be noted that the depth of sediment sample is $10 \mathrm{~cm}$, and recorded scouring depth in the experiment is $0.47-7.91 \mathrm{~cm}$. It should be noted that the vertical change of density along the depth of the sample is not considered in this study.

\section{Shear stress calculation}

According to the study of Bathurst (1985), relationship between average velocity $U$ and wall shear stress $\tau$ in the rectangular tube should follow the common formula for the shear velocity $u_{*}=\sqrt{\tau / \rho}=\sqrt{\lambda / 8 U}$, the factor of friction $\lambda$ can be expressed as follows: $\lambda=\frac{8 \tau}{\rho U^{2}}$

where $\rho$ is water density, and wall shear stress $\tau$ can be calculated if $\lambda$ is known.

Additionally, previous studies such as Nicholas indicated that the factor of friction $\lambda$ can be calculated using empirical formula as below:

(i) For the hydraulically smooth area: shear Reynolds number $R_{e^{*}}=\frac{\Delta u_{*}}{v}<5$ or $\frac{\Delta}{\delta_{0}}<0.4$,

Paula Theseus formula : $\lambda=\frac{0.316}{R_{e}^{1 / 4}} 4000<R_{e}<10^{5}$

Nicholas formula : $\frac{1}{\sqrt{\lambda}}=21 g\left(R_{e} \sqrt{\lambda}\right)-0.8 \quad R_{e}<10^{6}(4)$

(ii) For the area between hydraulically smooth and rough: $5 \leq=R_{e^{*}} \leq 70$ or $0.4 \leq \frac{\Delta}{\delta_{0}} \leq 6$,

White formula : $\frac{1}{\sqrt{\lambda}}=-2 \lg \left(\frac{2.51}{R_{e} \sqrt{\lambda}}+\frac{\Delta}{3.7 d}\right) \quad 3000<R_{e}<10^{6}$

(iii) For the hydraulically rough area: $R_{e^{*}}>70$ or $\frac{\Delta}{\delta_{0}}>6$,

Nicholas formula : $\lambda=\frac{1}{\left[21 g\left(3.7 \frac{d}{\Delta}\right)\right]^{2}} \quad R_{e}>\frac{191}{\sqrt{\lambda}}\left(\frac{d}{\Delta}\right)$

where, $\Delta$ is absolute roughness, and $\delta_{0}$ is the viscous sublayer, $v$ is kinematic viscosity, which is related with water temperature, and $d$ is the tube diameter.

In current experiments, the flow discharge in current experiments ranged from 3.68 to $21.64 \mathrm{~m}^{3} / \mathrm{h}$, the Reynolds number $R_{\mathrm{e}}$ in a rectangular tube can be expressed as:

$R_{e}=\frac{U h_{d}}{v}$

where, $h_{\mathrm{d}}$ is rectangular height. $R_{\mathrm{e}}$ it is less than $10^{5}$ ranging from 7681 to 49607 .

Additionally, sediment sample in the experiments was fine sediment; bed surface before scour experiment was generally smooth; the absolute roughness $\Delta$ was generally less than 
$0.046 \mathrm{~mm}$ (the maximum median particle size). The shear velocity $u_{*}$ in the experiment less than $0.10 \mathrm{~m} / \mathrm{s}$. When shear velocity $u_{*}$ is $0.10 \mathrm{~m} / \mathrm{s}$, the corresponding wall shear stress $\tau$ is $10 \mathrm{~N} / \mathrm{m}^{2}$, the calculated shear Reynolds number $R_{e *}$ less than 7.2. As thus, Eqs. (3) and (4) are suitable to calculate factor of friction $\lambda$ in this study, and wall shear stress $\tau$ could be obtained using Eq. (2) then.

\section{Experimental results}

According to Eq. (2), the flow velocity was obtained by dividing the discharge by the area of rectangular pipe section. During the period of consolidation, the deposition was getting denser progressively, and eventually to relatively high dry density and strong cohesion. After being consolidated from 1 to 377 days, each deposition sample's dry bulk density was measured. Figure 3 shows the variation of dry bulk density at different consolidation stages, which reveals that (i) the dry bulk density increased rapidly at the beginning of consolidation, and followed by slow increase after several months; (ii) only a few groups could reach their steady states after a consolidation time of 377 days.

\section{Influencing factors on incipient shear stress of cohesive sediment}

\section{Influence of consolidation times on incipient shear stress}

During the consolidation process of cohesive sediment, the deposition compressed slowly, and pore water percolated out gradually. In general, the deposition-consolidation process lasts a long time so that the values of cohesive force and shear strength vary with the consolidation time. Accordingly, the scour resistance of the deposition differs significantly for different consolidation time (Fig. 4, Tan et al. 2007a).

Fig. 4 shows that the incipient shear stress, $\tau_{c}$, of sediment sample increased over consolidation time. Moreover, the

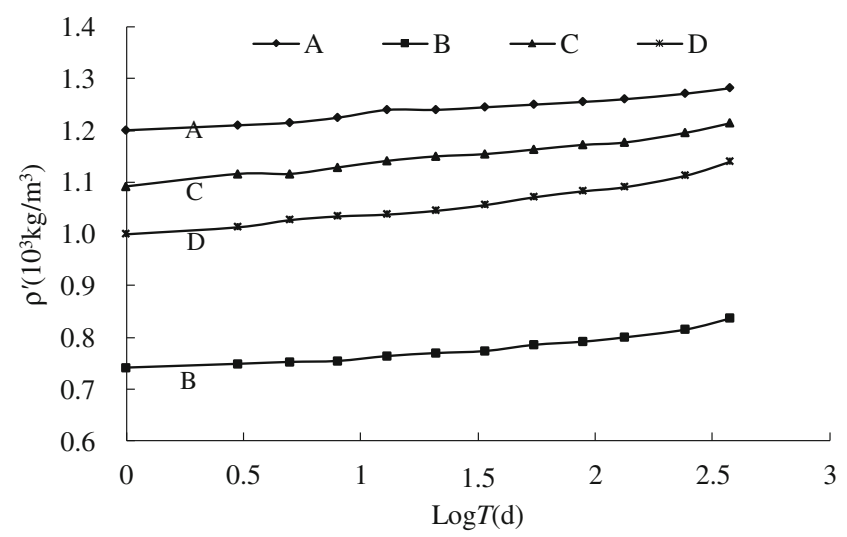

Fig. 3 Dry bulk densities versus consolidation times increased rate was different for different sediment groups. During the deposition process of 377 days, the values of incipient shear stress for group A was 0.30 to $0.47 \mathrm{~N} / \mathrm{m}^{2}$, with a smallest increase of $57 \%$; the values for group $\mathrm{C}$ ranged from 0.63 to $2.21 \mathrm{~N} / \mathrm{m}^{2}$, with a maximum increase of $251 \%$; and the increased percentages of incipient shear stress for group B and group D were $207 \%$ and $208 \%$, respectively.

Since it is very difficult to accurately measure the deposition time under natural conditions, the concept of relative dry bulk density $\rho_{d}$ was introduced herein. According to Chien and Wan (1999), a function of dry bulk density and consolidation time is expressed as:

$\rho^{\prime}=\rho_{s 1}^{\prime}+B \log t$

where $\rho_{s 1}^{\prime}$ is the dry bulk density in the first year after consolidation, termed as the initial dry bulk density. And relative dry bulk density, $\rho$, is defined as:

$\rho_{d}=\frac{\rho^{\prime}}{\rho_{s 1}^{\prime}}=1+\frac{B}{\rho_{s 1}^{\prime}} \log t=f(t)$

As indicated by Eq. (6), if other factors remain unchanged, $\rho_{d}$ is influenced by the consolidation times and can be calculated by the measured $\rho^{\prime}$ and $\rho_{s 1}^{\prime}$ In this way, the difficulties of measuring the consolidation times can be effectively overcome.

\section{Effect of dry bulk density on the incipient shear stress}

The dry bulk density depends on the sediment composition and particle shape, etc. For example, the dry bulk density increased when the median diameter increased (Shu et al. 2009). However, for certain sediment deposition, the dry bulk density slowly increased as the consolidation time increased. Such different evolution of the dry bulk density for different kinds of cohesive sediment influenced the variation of incipient shear stress.

The relationships between the dry bulk density and incipient shear stress for different sediment groups are plotted in Fig. 5. It shows that the incipient shear stress increased as the dry bulk density increased. For instance, the incipient shear stress for group B increased from 1.91 to $5.86 \mathrm{~N} / \mathrm{m}^{2}$ when the dry bulk density varied from 0.74 to $0.84 \times 10^{3}$ $\mathrm{kg} / \mathrm{m}^{3}$. Moreover, these curves in Fig. 5 also indicate that dry bulk density affected the incipient shear stress differently for various deposition samples. It should be noted that the incipient shear stress increased as the content of cohesive particles increased (Fig. 6).

For the same sediment sample, the incipient shear stress increased with the increasing dry bulk density, which indirectly demonstrated the relationship between the incipient shear stress and consolidation time. For different sediment samples 
Fig. 4 Relationships between the incipient shear stress and consolidation time for different groups

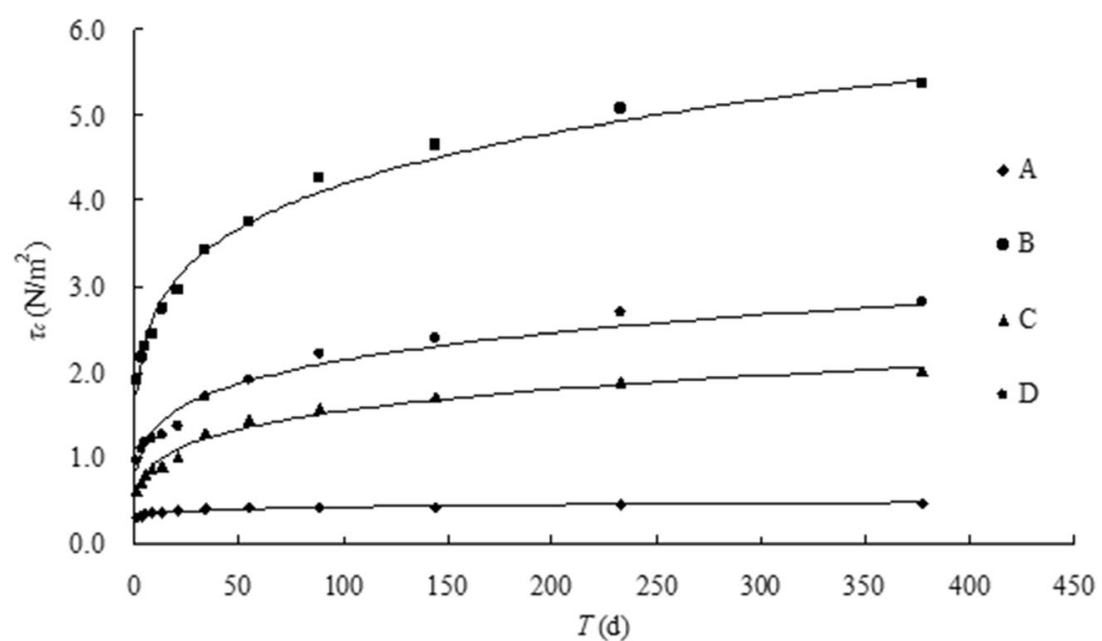

with the same consolidation time, the larger of the particle sizes in the sample, the greater of the dry bulk density. Since the main force resisting scouring was the cohesive force, the cohesive sediment particles with larger sizes could be scoured more easily than those particles with smaller sizes.

\section{Influence of the cohesive particle content on incipient shear stress}

The content of cohesive particles in the deposition sample $\left(P_{c}\right)$ is one of the most important factors that influences the magnitude of cohesive force. The cohesive sediment particles are very fine with large surface areas. Therefore, they are subjected to intensive physical and chemical effects. These effects are caused by the presence of an inner cohesive force.

However, previous researches rarely introduced the content of cohesive particles, even if this factor was closely related to the incipient shear stress. Figure 4 also shows the relationship between $P_{c}$ and $\tau_{c}$ for different sediment samples under the same consolidation time. It can be seen that the higher of the content of cohesive particles, the greater of the incipient shear stress. Consequently, cohesive sediment with a higher $P_{c}$ scoured less easily.

Fig. 5 Relationships between the incipient shear stress and dry bulk density for different groups

\section{Analysis of influencing factors}

As discussed earlier, the value of incipient shear stress significantly depended on the consolidation time, the dry bulk density, the content, and mineral composition of cohesive particles. Since a logarithmic relationship between the dry bulk density and consolidation time has been observed, the variable of consolidation time can be implicitly expressed as a function of the relative dry bulk density. The most important factor that influenced the cohesive force was cohesive particle content, which further affected the incipient shear stress.

For the same sediment sample, the incipient shear stress increased with the dry bulk density, which is consistent with the observation that a larger value of incipient shear stress would be obtained with a longer consolidation time. For different sediment samples, the deposition composition is different, and this may partially led to the difference in the relationship between the dry bulk density and incipient shear stress.

Generally, the consolidation time and content of cohesive particles were mutually independent, but both of them significantly influenced the incipient shear stress. The incipient shear stress increased with the increase of consolidation time and cohesive particle content.

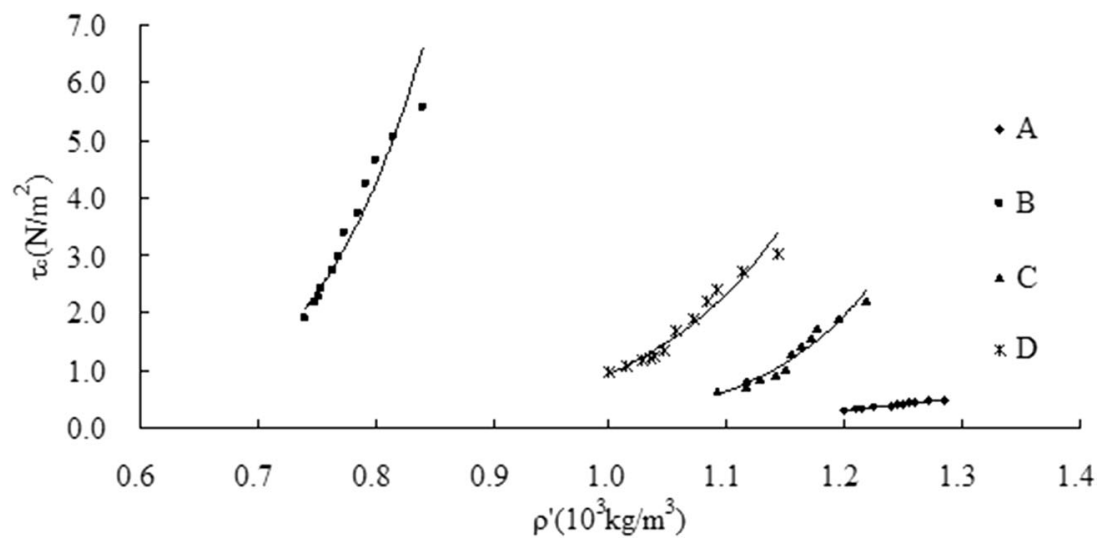




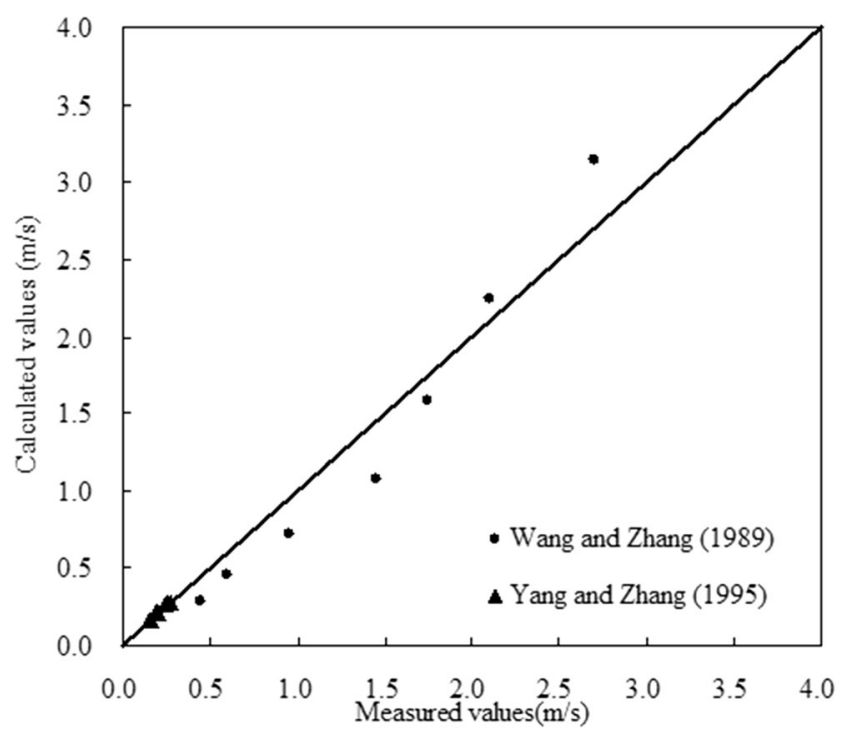

Fig. 6 Comparison between the calculated and measured velocities

\section{Incipient motion formula of cohesive sediment}

\section{Preliminary analysis of the incipient motion mechanism}

During consolidation, the forces and motion modes for the fine cohesive sediment were different from those for noncohesive sediment once the erosion process started. The noncohesive sediment was mainly affected by the hydrodynamic force and effective gravity, while the cohesive sediment was affected by the cohesive force between particles in addition to the two forces mentioned above (Bai et al. 2002).

During consolidation, the cohesive sediment was gradually compressed and formed a stable structure. The cohesive force between particles increased gradually, and became the main factor that resisted erosion. Thus, the stable structure and cohesive force between particles were generally the key influencing factors for the cohesive sediment erosion. During the consolidation process, the pore water between particles percolated out slowly, and the deposition was compressed slowly, so the dry bulk density increased gradually. Following Gu and Sun (2005), the inner cohesion force of soil, $C$, is the function of the ratio of water content to cohesive soil content $m$ and dry bulk density $\rho$ ', which can be expressed by:

$$
C=(-33 m+44) \times\left(3.75 \rho^{\prime}-4.32\right) \quad m<1.33
$$

Thus, the content of cohesive particles for the deposited sediment kept unchanged during the process of consolidation. With the decrease of water content, the value of $m$ decreased, and the value of $\rho^{\prime}$ increased, which led to the increase of $C$. In other words, it was more difficult for scouring to occur as the consolidation time increased (Fig. 7).

\section{Formula of incipient shear stress}

As discussed earlier, the values of incipient shear stress greatly depended on the consolidation time, the dry bulk density, and the content of cohesive particles. If the cohesive content and the composition of deposition sample remained unchanged, the consolidation time influenced the dry bulk density. According to Shu et al. (2008), the incipient shear stress is given by:

$\tau_{c}=k P_{c}^{\eta}\left(\frac{\rho^{\prime}}{\rho_{s 1}^{\prime}}\right)^{\varphi}$

where $k, \eta$, and $\phi$ are coefficients, which can be estimated using the least square method. Based on the 48 groups of data, the estimated values of $k, \eta$, and $\phi$ were $18.5 \mathrm{~N} / \mathrm{m}^{2}, 0.88$, and 10.3, respectively. Then, Eq. (8) can be rewritten as:

$\tau_{c}=18.5 P_{c}^{0.88}\left(\frac{\rho^{\prime}}{\rho_{s 1}^{\prime}}\right)^{10.3}$

where $P_{c}$ is a dimensionless parameter for the cohesive particle content, and the units of $\rho^{\prime}$ and $\rho_{s 1}^{\prime}$ are both $10^{3} \mathrm{~kg} / \mathrm{m}^{3}$. This equation can be used to estimate the incipient shear stress for sediment with $2-38 \%$ of cohesive particle content.

\section{Formula validation}

In order to assess the proposed formula, the experimental data obtained by Wang and Zhang (1989) and Yang and Wang (1995) were used. These data were obtained from the deposition observations from a reservoir and the Hangzhou Bay, with the median diameters of 0.004 and $0.0104 \mathrm{~mm}$, respectively and with the corresponding contents of cohesive sediment of $55 \%$ and $35 \%$. The incipient shear stress can also be represented by the incipient velocity. Figure 6 compares the predictions using Eq. (9) and the measured incipient velocities, and it can be seen that the calculated results agree well with the measured, especially for those with smaller incipient velocities.

\section{Conclusions}

Based on experimental and theoretical methods, this paper investigates the incipient motion mechanism of cohesive sediment, especially the impact factors of incipient shear stress including the consolidation time, dry bulk density, and cohesive particle content. A formula of incipient shear stress for cohesive sediment was 
Fig. 7 The relationships between inner cohesion force $\mathrm{C}$ and cohesive soil content $\mathrm{m}$

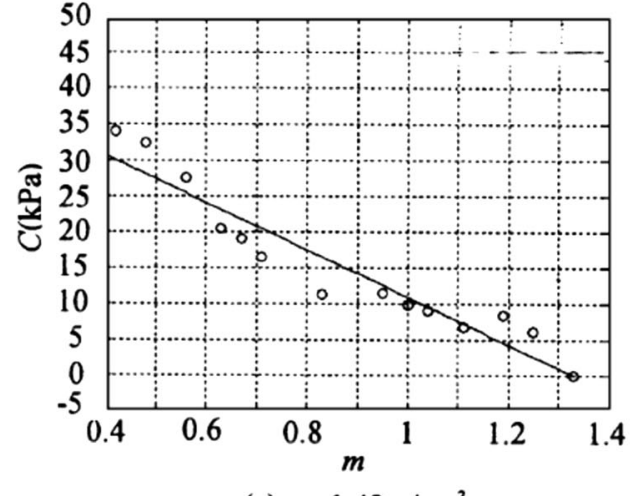

(a) $\rho_{\mathrm{d}}=1.42 \mathrm{~g} / \mathrm{cm}^{3}$

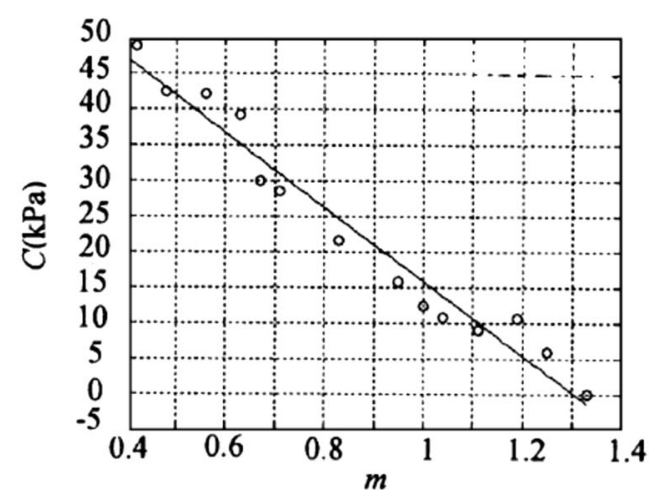

(b) $\rho_{\mathrm{d}}=1.57 \mathrm{~g} / \mathrm{cm}^{3}$ proposed and verified by the experimental data. The following conclusions can be drawn:

1. The incipient shear stress correlated closely with the consolidation time, dry bulk density, and cohesive particle content. The dry bulk density influenced the incipient motion due to the integrated influences of the consolidation time and composition of sediment mixtures. Therefore, the consolidation time and cohesive particle content were mutually independent, whereas both of them had a significant influence on the incipient shear stress. The magnitude of incipient shear stress increased with the increase of consolidation time and cohesive particle content. Consequently, cohesive sediment scoured less easily than noncohesive sediment.

2. The incipient motion mechanism of cohesive sediment was described. During the deposition process of cohesive sediment, with the pore water filtering out slowly, the distance between particles became shorter, and the cohesion force increased. Consequently, cohesive sediment scoured less easily as the consolidation time prolonged.

3. A formula of the incipient shear stress was derived for natural river conditions, and it was expressed as a function of content of cohesive particles and relative dry bulk density. Three parameters in the formula were determined by the experimental data, and the calculated values agreed well with the measured data.

Funding This study was supported by the National key research and development project (Grant No: 2018YFC0407801-1 and 2016YFC0402303).

Open Access This article is licensed under a Creative Commons Attribution 4.0 International License, which permits use, sharing, adaptation, distribution and reproduction in any medium or format, as long as you give appropriate credit to the original author(s) and the source, provide a link to the Creative Commons licence, and indicate if changes were made. The images or other third party material in this article are included in the article's Creative Commons licence, unless indicated otherwise in a credit line to the material. If material is not included in the article's Creative Commons licence and your intended use is not permitted by statutory regulation or exceeds the permitted use, you will need to obtain permission directly from the copyright holder. To view a copy of this licence, visit http://creativecommons.org/licenses/by/4.0/.

\section{References}

Bai YC, Chiu-on NG, Shen HT, Wang SY (2002) Rheological properties and incipient motion of cohesive sediment in the Haihe Estuary of China. Chin Ocean Eng 16(4):483-498

Bathurst JC (1985) Flow resistance estimation in mountain rivers. J Hydraul Eng Amsterdam 111(4):625-643

Chien N, Wan Z (1999) Mechanics of sediment transport, American Society of Civil Engineers. ASCE Press, Virginia

Dune JS (1959) Tractive resistance of cohesive channels. J Soil Mech Found Div ASCE 85(SM3):1-24

Gu CQ, Sun Y (2005) Discussion on the cohesion of soil changing with water content, cohesive coil content and dry density. Hydrogeol Eng Geol 31(2):34-36 (in Chinese)

Kothyari U, Jain R (2008) Influence of cohesion on the incipient motion condition of sediment mixtures, Water Resour Res 44

Krone RB (1962) Flume studies of the transport of sediment in estuarial shoaling processes. Technical Report, Hydraulic Engineering Laboratory and Sanitary Engineering Research Laboratory, University of California

Krone R (1993) In: Mehta AJ (ed) Sediment revisited. Nearshore and estuarine cohesive sediment transport. American Geophysical Union, Washington, D.C., pp 108-125

Liem R, Spork V, Koengeter J (1992) Investigations on erosional processes of cohesive sediment using an in-situ measuring device. Int $\mathrm{J}$ Sediment Res 12(3):139-147

Lin CHK (1992) The source of cohesive sediment and its transport in the Yangtze estuary and near sea. Int J Sediment Res 7(2):85-97

Maa JP, Kim S (2002) A constant erosion rate model for fine sediment in the York River, Virginia. Environ Fluid Mech 1(4):345-360

Maa JP, Kwon J, Hwang K, Ha H (2008) Critical bed-shear stress for cohesive sediment deposition under steady flows. J Hydraul Eng 134(12):1767-1771

McNeil J, Taylor C, Lick W (1996) Measurements of erosion of undisturbed bottom sediments with depth. J Hydraul Eng 122(6):316-324

Mehta AJ (1973) Depositional behavior of cohesive sediments. Ph.D. dissertation, University of Florida, Gainesville, Florida

Mehta AJ, Partheniades E (1975) An investigation of the deposition properties of flocculated fine sediments. J Hydraul Res 12(4):361381 
Roberts JR, Lick W (1997) Long beach harbor sediment study. Report to the U.S. Army Corps of Engineers, Los Angeles District

Roberts JR, Lick W (1998a) New York harbor sediment study. Report to the U.S. Army Corps of Engineers, New York District

Roberts JR, Lick W (1998b) Effects of particle size and bulk density on erosion of quartz particles. J Hydraul Eng 124(12):1261-1267

Roberts JR, Lick W (1999) Effects of gas generationon the density and erosion of sediments from the Grand River. J Great Lakes Res 26(2): 209-219

Sediment Specialty Committee of Chinese Hydraulic Engineering Society (1992) Handbook of sediment. Chinese Environmental Sciences Press (in Chinese)

Sharif A (2003) Critical shear stress and erosion of cohesive soils. PhD dissertation. Department of Civil, Structural, and Environmental Engineering, University of New York at Buffalo

Shu CW, Tan GM, Wang J (2008) Study of influence on cohesive deposits incipient motion and erosion by dry bulk density. Adv Water Resour Hydraul Eng:1131-1136

Shu, C. W., Tan, G. M., and Wang, J. 2009, Study of influence on cohesive deposits incipient motion and erosion by dry bulk density. Adv Water Resour Hydraul Eng, Vol. III, 1131-1136. https://doi. org/10.1007/978-3-540-89465-0_197

Singh UK, Ahmad Z, Kumar A (2017) Formulation for critical shear stress of cohesive sediment mixture. Curr Sci 113(11)

Tan GM, Chen YM (2016) Experimental study of cohesive sediment consolidation and its effect on seepage from dam foundations. Int J Sediment Res 31:53-60

Tan GM, Shu CW, Wang J (2007a) Simplified flume experimental study on the eroding influence by consolidation times. Proceedings of 10 th congress of the International Symposium on River Sedimentation. Moscow, Russia, Vol.II, pp 393-401
Tan GM, Wang J, Shu CW et al (2007b) Effects of consolidation times and particle size on scour rates of cohesive sediment. J Hydrodyn Ser B 19(2):160-164

Toorman ER (2002) Modeling of turbulent flow with suspended cohesive sediment. Proc Mar Sci Amsterdam, The Netherlands 5:155-169

Wang PQ, Cai RR (2014) Effect of sediment consolidation time on dry density and incipient motion and scour. Yellow River 36(5):22-23 (in Chinese)

Wang ZY, Hu CH (2009) Strategies for managing reservoir sedimentation. Int J Sediment Res 24(4):369-384

Wang ZY, Zhang XY (1989) Study on model test of cohesive sediments on scouring of reservoir emptying. J Sediment Res 2:62-68 (in Chinese)

Winterwerp JC (2002) Scaling parameters for high-concentrated mudsuspension in tidal flow. Proc Mar Sci Amsterdam, The Netherlands 5:171-186

Winterwerp JC (2007) On the sedimentation rate of cohesive sediment. Estuarine and coastal fine sediment dynamics. Proceedings in Marine Science. Amsterdam, the Netherlands, pp 209-226

Wu WM, Sam SY, Wang (2004) Depth-averages 2-D calculation of tidal flow, salinity and cohesive sediment transport in estuaries. Int $\mathrm{J}$ Sediment Res 19(3):172-190

Xu D, Bai Y, Ji C, Williams J (2015) Experimental study of the density influence on the incipient motion and erosion modes of muds in unidirectional flows: the case of Huangmaohai Estuary. Ocean Dyn 65:187-201

Yang MQ, Wang GL (1995) The incipient motion formulas for cohesive fine sediments. J Basic Sci Eng 3(1):99-109 (in Chinese)

Zhang QH, Yan B, Wai OWH (2009) Fine sediment carrying capacity of combined wave and current flows. Int J Sediment Res 24(4):425-438

Zheng FD, An JF (2017) Study on the Critical Shear Stress of Cohesive Sediments. IOP Conf Ser Earth Environ Sci 100(1):012204 